\section{The Necessity of Peer Review}

\author{
S.M. Fazlul Karim
}

Vice Principal and Professor \& Head of the department

of Biochemistry,

Delta Medical College, Dhaka, Bangladesh

\&

Editor-in-Chief,

Delta Medical College Journal

Publication of scientific journal from an institution like Medical College is highly prestigious. It is essential for updating knowledge, developing professional skill and encouraging research.

Every scientific journal must have a careful planning and thought to maintain its quality to make it highly educational.

Every piece of scientific writing is built on four elements: relevance, structure, style and accuracy. Relevance and structure are most efficiently addressed while brainstorming paper and developing an outline. But style and accuracy are best improved while revising/reviewing the paper.

Writing and revising at the same time (commonly referred to as the 'brain dump') does not work. In many cases another individual can check the accuracy of his data. He always does this by technical proofread with fresh focused "eyes". It would be surprised how many mistakes are to be discovered after reviewing the paper. ${ }^{1}$ Therefore to avoid these mistakes and inaccuracy for publishing an article requires careful review, with an appropriate and detailed analysis of methodology, logic and the quality and rigor of the work. There are many processes of reviewing such as Peer review, Cochrane review, Post-hoc Review, etc. Among these Peer review is used extensively in a variety of professional fields including biomedical research prior to publication. Arman Yuri Gasperyan and George D. Kitas in their article 'Best peer reviewers and the quality of peer review in biomedical journals' in Croat Med J. published in August 2012, had commented "Current scholarly publications heavily rely on high quality peer review". ${ }^{2}$
The word peer is often defined as a person of equal standing. However, in the context of peer review it is generally used in a broader sense to refer to people in the same profession who are of the same or higher ranking. Many one defines peer review in different ways on the basis of concept of creative work and performance.

However, most accepted meaning of peer review is: the evaluation of creative work or performance by other people in the same field in order to maintain or enhance the quality of work or performance in that field. ${ }^{3}$

Peer review involves reviewing papers submitted to a journal by (usually) two individuals in isolation. Following this they submit their critique to the editor, together with (if requested) their recommendation with respect to dispensation for publication, with an accompanying rationale highlighting any changes and work by which the paper could be improved. Sometimes, reviewers and/or editors request that a further opinion is sought from another specialist reviewer such as statistician. Indeed many journals will, as a matter of course, seek statistical advice on each paper. 4

$\mathrm{J}$ Iredale, Professor of Medicine, Dean of Clinical Medicine and Director of MRC Center for Inflammation Research, University of Edinburgh and Dr. R AI-Shahi Salman, Senior Clinical Fellow, Honorary Consultant Neurologist, University of Edinburgh, Edinburgh, UK, pointed out the value of peer reviewing and recommended that this activity should be recognized for continuous professional development in the editorial of 'The Journal of the Royal College of Physicians of Edinburgh' published in December 2012.4 
Although peer review also a bit flawed and has some drawbacks like biasness, increase cost of publishing and time consuming, despite of these disadvantages, the necessity of peer review to improve the accuracy and quality of scientific works as well as scientific journals are very essential.

Editorial choice of the reviewers can avoid cronyism i.e. favoritism shown to relatives, colleagues and friends for impartial evaluation. The reviewers should not be selected from among the close colleagues, relatives or friends but should be selected from different places.

Therefore, a peer review journal article requires careful planning and thought.

Delta Med Col J.Jul 2013;1(2):29-30

\section{References}

1. Cappallen VLKV. Writing tips for peer-review journal articles [Internet]. [cited 2013 March 16]. Available from: http: //shadow.eas.gatech.edu/ jean/ paleo/ Writing_tips.pdf.

2. Gasparyan YA, Kitas G D. Best peer reviewers and the quality of peer in biomedical journals. Croat Med J. 2012;53(4):386-89.

3. Peer Review definition [Internet]. The Linux Information Project [cited 2013 March 16]. Available from: http://www.linfo.org/peer_review.html.

4. Iredale J, Salman SRA. Peer review: a flawed but essential process [editorial]. JR Coll Physicians Edinb. 2012;42:290-91. 